\title{
TOWARDS APPRAISAL AND IMPROVEMENT OF PROJECT MANAGEMENT PRACTICES FOR EGYPTIAN CONSTRUCTION CONTRACTORS
}

\author{
Mohamed H. Moutawei ${ }^{1}$ and Moheeb E. Ibrahim ${ }^{2}$ \\ ${ }^{1}$ Orascom Construction Industries, Cairo, Egypt. \\ 2 Structural Engineering Department, Faculty of Engineering, Cairo University.
}

\begin{abstract}
Project Management has evolved and emerged by several organizations not only to gain competitive advantage; but also as a crucial factor that determines the success of the organization. In this regard, there is a global growing interest and attention for organizations to evaluate and improve the level of their project management practices. The past decade has shown a dramatic increase in the attention, research and practice of the project management maturity and the maturity models. These models are used to evaluate the current project management capabilities of an organization and to ensure its efficiency and uniformity in delivering projects successfully. Moreover, these models are used to further enhance the performance of organizations. Although the maturity models has evolved during the last decade as one of the tools for achieving project management excellence on the organization level; however, the excessive variety of maturity models has made the choice between those models difficult and need careful attention and consideration in both the model choice and its practical implementation in the business.

For developed countries (such as USA, Canada, UK, Europe, etc...) several maturity models have been proposed and commonly implemented successfully. In Egypt, there is a lack of documentation available on the current status and use of maturity models in the contracting organizations working in the construction industry. This paper constitutes a part of a larger research project aims to fill this gap. To achieve this, an extensive literature review has been conducted on the predominant existing maturity models, a market survey to assess the current status of maturity awareness in the construction contracting organizations has been developed and the basis of integrated framework for appraisal and improvement of project management practices for the contracting organizations working in the Egyptian construction industry have been proposed.
\end{abstract}

Keywords: Construction Industry, Egypt, Project Management.

\section{INTRODUCTION}

The construction industry is one of the largest industries in the world and plays significant role in the economy of both developed and developing countries. In leading industrial countries, construction investment, expressed as percentage of gross national product ranges from approximately $4 \%$ in USA and $6 \%$ in Canada to $7 \%$ in UK and $10 \%$ in Japan. For developing countries, major construction activities account for approximately $80 \%$ of the overall capital assets, $10 \%$ of their GDP, and greater than $50 \%$ of the wealth invested in fixed assets. Additionally, the construction business offers great employment opportunity, possibly next after agriculture [1]. Moreover, the construction industry provides physical facilities satisfying a wide variety of social, economic and technical needs. In addition, it is the backbone of a variety of secondary feeding industries through which it acts as a major source of employment and upgrading of specialized skills. 
The pivotal role of management practices in construction projects has become a crucial factor for the success of the construction organizations. The role of project management in construction has become well researched. Among the mainstream understandings is that poor managerial capabilities are one of the crucial problems in the construction industry. Globalization, business environmental has posed several kinds of challenges to these organizations. As a result, some construction organizations are seeking their profitability and survival in enhancing the efficacy of their management practices to achieve the organizational objectives. An Organization's current capabilities in managing projects can be evaluated using project management (PM) maturity models. Maturity Models are models designed to provide a way for organizations to understand their organizational project management practices and to evaluate their maturity against an extensive set of best practices for organizational project management. In other words, PM maturity models are models developed to help organizations determine their level of maturity in their project management practices. However, with dozens of contemporary maturity models [2] [3] in the project management field, organizations have to consider very carefully the one that they could adopt. Organizations have to consider the essential aspects of these models and how they should evaluate them.

Through the selection of the maturity model and the correct practical implementation in the business, the strengths and weaknesses of the organizational project management practices can be well identified with a structured roadmap for improvement of these practices.

\section{STATEMENT OF THE PROPLEM}

In spite of the construction industry's substantial involvement in the overall economy of developing countries and the critical role it plays in the development of these countries, the performance of the industry still remains generally low. As Idoko (2008), noted, "...many projects in developing nations encounter significant cost and time overruns, fail to realize their aimed benefit or may be even completely terminated and abandoned before or even after their completion..." [4]. Moreover, the development of the construction industry in developing nations usually lags significantly behind from other industries in those nations and also their counter parts in developed nations. Generally, as Ofori (2006) concluded "The construction industry in developing nations failed to fulfill expectations of customers, governments and even society as a whole" [1].

Similar to the case along with other developing nations, the Egyptian construction industry shares most of the problems and challenges the industry is facing in other developing nations, maybe with greater severity. Given that, Egypt, as a developing country, needs several major national projects like water, wastewater, and transportation projects; also, considering the critical role the construction industry plays in Egypt and other developing countries, and the poor level of performance of the industry in these countries, improving the overall performance of the construction industry ought to be a high priority action.

Since contractors are among the crucial players in the construction industry and the makers of the end product, any level of development and enhancement initiatives in the industry should consider improving the capacity and capability of the contractors. Given that there are a lot of unprecedented Mega and Giga projects in the region and that the Egyptian contractors have a great opportunity to export their contracting services in the region and increasing the national income and the employment opportunities; moreover, considering, the competition in the region is becoming very tough and challenging; as new and international contractors (including Chinese and Indian companies) are emerging into the market. Furthermore, Improving the capacity and capability of Egyptian contractors has been announced by the Egyptian government to be one of its priorities [5], improving the capacity and capabilities of Egyptian contractors ought to be a high priority action. Earlier research works by several authors, such as, Adams [6] and Long [146] [7] have showed poor managerial capability of contractors to be certainly one of the crucial problems of the construction industry in developing nations. Thus, improving the managerial capability of contractors need to be one 
of the priority considerations for improvement. Researches by (Dlungwana \& Rwelamila) have also strongly emphasized the importance of enhancement the management skills of contractors [8]. Systematic and continuous development exertion needs understanding of exactly where the present status of the management practices is, where desired to go, and the gap between the two. Additionally, systematic and sustained enhancement endeavor demands identifying critical and priority areas, continually assessing results of improvement efforts and taking appropriate actions. So far, there is a lack of research and documentation in Egypt in this regard. This paper constitutes a part of a larger research project is thus undertaken to fill this gap.

\section{RESEARCH OBJECTIVES}

This paper constitutes a part and a preliminary step of a larger research project focusing on assisting the Egyptian construction contractors in evaluating and improving their project management practices and capabilities. The main objective of this paper is to review the literature, facilitate the contracting organizations to understand the predominant various models and its strengths and weaknesses. The second objective of this paper is to present the survey for the assessment of the current status in the Egyptian Contracting organizations and the preliminary results received till date. Finally, the basis for the development of integrated framework for appraisal and improvement of the project management practices for the Contracting organizations working in the Egyptian construction industry will be presented. These bases will be utilized to propose a new approach for future implementation in the light of both the strengths and weaknesses of the current models and the current status of the Egyptian contracting organizations.

\section{RESEARCH METHODOLGY}

To achieve the required objectives of this paper, the paper first reviews the literature and how the problem was solved on both the Practitioner's and Academic levels worldwide. Then the paper reviews the maturity concept, definitions, basics, evolvement and models. Third, a comparison study between the predominant models to identify the strengths and weaknesses of each maturity model. Fourth, a survey questionnaire is developed to assess the current status of the contracting organizations working in the Egyptian construction industry. Fifth, the findings of the comparison study of the maturity models and the preliminary results and samples of the survey have given preliminary directions and guidelines for the development of the framework. Finally the findings, conclusion, the way forward and the future steps have been presented. Fig. 1 presents the steps followed in this paper.

\section{LITERATURE REVIEW}

\section{Importance of Project Management Maturity:}

Project management is being grasped, to some degree, by most organizations as the most ideal approach to create and convey new and enhanced results, services, products and organizational procedure changes [9]. During the past two decades, not only there has been a growth in the number of organizations implementing project management [10], but also, we certainly have observed a dramatic increase in the extent of which modern organizations adopts and depends on project management to secure a more competitive advantage [11]. One of the triggers of this ever growing prominence can be observed in the massive amount of publications created about the subject. It has been a consistent exertion of specialists and professionals to search for approaches to establish and also improve the project management capabilities for organizations so that organizations may have the capacity to benefit from project management. 


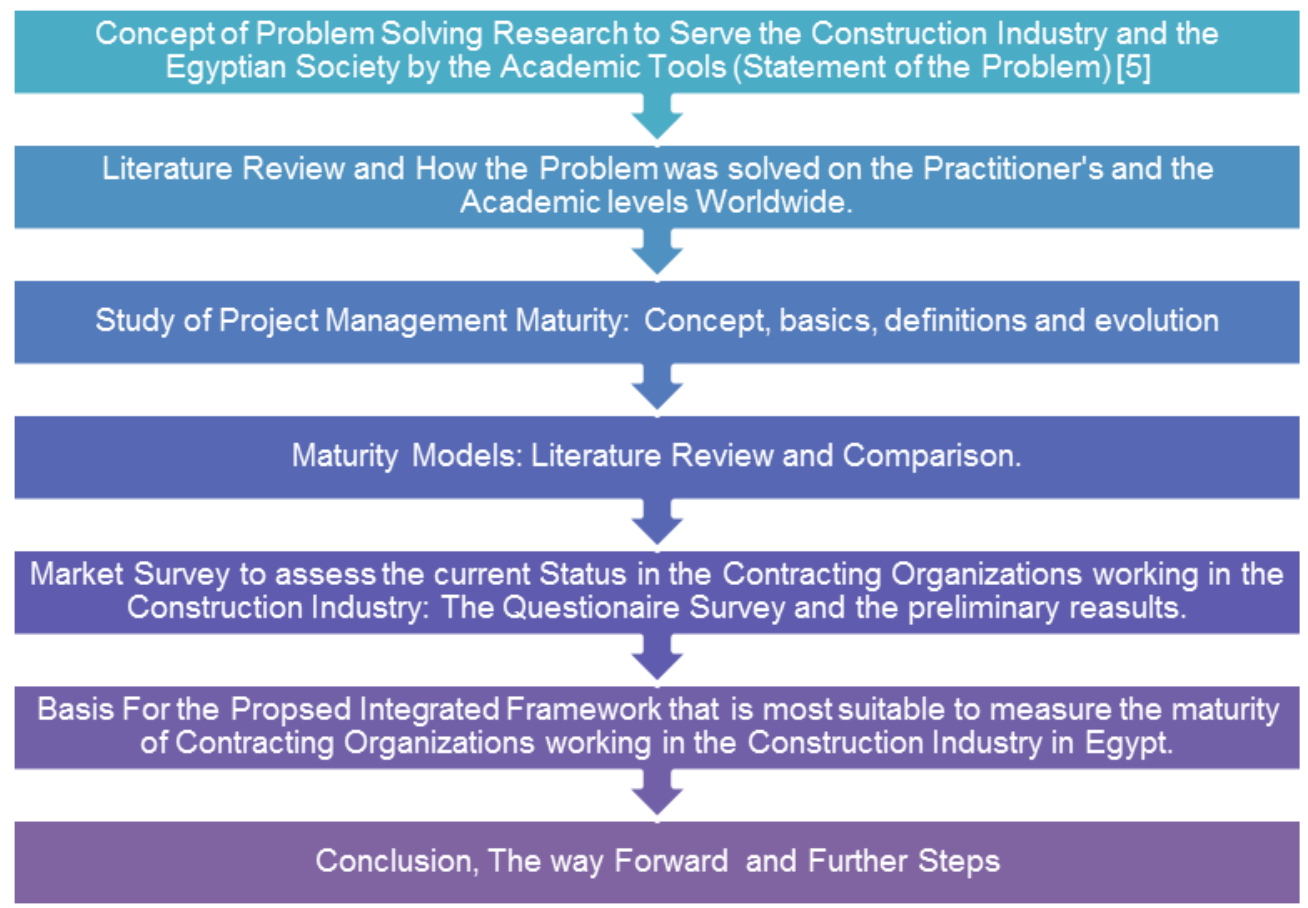

Fig. 1: Flow Chart for Research Methodology

Although, the enhancement of project management practices of an organization can be realized in a wide range of methods such as training, mentoring, benchmarking, the use of new tools and techniques and use of Project management maturity models, etc. and maybe project Management Maturity models are just one of such means that organizations can utilize in their pursuit of improving their Project Management practices [12] [9] [13]. However, the first step in any enhancement effort is the evaluation of the current status. This evaluation should guide and draw the roadmap for the correct and effective road map for the improvement. This leads to the discourse of maturity models that are established to enable organizations to evaluate and enhance exactly how project management practices are performed and to help organizations to carry out successful projects on a regular basis.

According to Cooke-Davies, the utilization of maturity models in project management provides a frame work for purposeful and progressive improvement of project management practices of repeatedly delivering successful projects [12]. Maturity Models in general, can assist an organization to know how professional or mature its project management practice is; that is, it helps the organization measure the extent to which it is executing Project management against the practice of its competitors in the same industry in general or even the best practices in the industry. Also, maturity models help outline enhancement endeavors by highlighting priority areas and proposing areas and way of enhancement.

\section{Maturity: Basics, Concepts, Definitions and Evolution:}

Maturity, in general usage, means completely created or consummated. It is defined by several authors in different ways with closely relevant manner. A number of these definitions is presented below.

Paulk, Curtis \& Weber believe that "Maturity is the extent to which a specific process is explicitly defined, managed, measured, control and effective. Maturity implies a potential for growth in capability and indicates both the richness of an organization's PM process and the consistency with which it is applied in projects throughout the organization" [14]. Both Ibbs and Kwak think that "Maturity is the sophistication degree of an organization's present practices and processes for project management" [15]. Moreover, Bolles defined maturity as the current level of project management knowledge and skills in the organization [16]. 
In the definition of CMMI "Organizational Maturity is the extent to which an organization has explicitly and consistently deployed processes that are documented, managed, measured, controlled, and continually improved" [12]. Kerzner has defined maturity in project management as "implementation of a standard methodology and accompanying processes such that there is a high likelihood of repeated successes" [20]. In the definition of PM Solutions institute "..... (Maturity) is a comparative level of advancement an organization has achieved with regard to any given process or set of activities. Organizations with more fully defined and actively used policies, standards, and practices are considered more mature" [17]. PMI (2013) has defined maturity as "The degree to which an organization practices project management measured by the ability of an organization to successfully initiate, plan, execute, monitor and control individual projects" [19]. Prado and Archibald (2014) defined project management maturity as "the mechanism to numerically quantify the capability of an organization to manage its projects successfully" [18].

What appears regular in the majority of the previous definitions is the concept of consistent and also recurrent practice, evaluation and enhancement. "As an organization gains in (project management) process maturity, it institutionalizes its project management process via policies, standards, and organizational structures. Standardization (requests) building infrastructure and a corporate culture that supports the techniques, practices, and methods of the organization so that they continue after the individuals who initially characterized them have gone" [14]. As outlined by Kerzner, "Maturity in project Management is a never ending journey, with never-ending cycle of bench-marking and continuous improvement" [21]. The more mature an organization is, the predictability, effectiveness and also control over the procedures of the organization are anticipated to be enhanced [14] and the more probable the organization meets its objectives effectively [17]. As mentioned in [23], matured processes are extremely recognized throughout a mature organization. Although, there is no absolutely in general consented definition of exactly what a mature organization seems like [12]. However, it is normally by means of documentation, training, along with the procedures are regularly to be watched and improved by its team members. According to Sarshar, "generally, in a matured organization, a disciplined process is consistently followed because all of the participants understand the value of doing so, and the necessary infrastructure exists to support the process" [25]. The maturity process means that the efficiency and high quality as a result of the organization's use of the processes can be improved over time by means of regular gains in the disciplines achieved by using the procedures [23]. In other words, "An organization that is mature in project management has an organization-wide ability for managing initiatives based on standardized and defined management processes. In such organizations, activities are carried out according to defined processes and plans. Roles and responsibilities are well defined and understood. Such organizations have also an objective way of measuring performance and quality; and the necessary information and database for doing that" [(Office of Government Commerce (OGC)) [24].

On the contrary, "An organization that is immature in project management may occasionally deliver individual (projects) that produce excellent results. However, in such cases managers are more likely to be working reactively, focusing on solving immediate issues, rather than proactively acting. In addition, schedules and budgets are likely to be exceeded and if deadlines are imposed, the quality of deliverables is likely to be compromised in order to meet the schedule. In an immature organization, repeatable processes and results depend entirely on the availability of specific individuals with a proven track record." (OGC). As mentioned by Sarshar, an immature organization is an organization which does not have or even utilize regular and identified processes to manage the projects [25]. As stated by Paulk, "As maturity increases, the variability of actual results around targeted results decreases. For instance, in an immature organization delivery dates for projects of similar size are unpredictable and vary widely. However, similar projects in a matured organization are expected to be delivered within a much smaller range. This narrowed variation occurs at the highest maturity levels because virtually all projects are performing within controlled parameters approaching the organization's process capability" [14]. 
Gaining maturity will not actually pledge automatically achieving success for projects. Nevertheless, it would improve the chances of achieving success for projects. It needs to be mentioned that the process of getting maturity is not a one-time occasion which is completed by announcing a framework and method, nor it is a fast repair for quick tactical problems rather, it is really a consciously organized as well as adequately managed continuous enhancement committed work [24] [19] [27].

As stated by (Crawford, 2015), until lately the "Maturity" concept was rarely utilized to describe the effectiveness of organizations to perform specific tasks [22]. However, a fast evolution in the publications of articles relevant to maturity has been seen during the last 20 years [28]. An organized keyword research was conducted by Nesensohn et al. (2014) concentrated on the appearance of the term 'maturity' in abstracts of periodicals related to management and engineering for almost two decades starting from 1990 till 2013. The research was conducted in 4 databases, which are: Emerald, Scopus, Business Source Complete, and Discover. The exact number of articles per database for every year was compiled and utilized to estimate the growth rate for each database per year; it is outlined in Figure 2. As presented in Figure 2, it is being significantly hard to disregard the greater consideration provided to the word 'maturity' within engineering and business management journals since the 1990s and it emphasize the spurt in growing of articles with maturityrelevant topics [29].

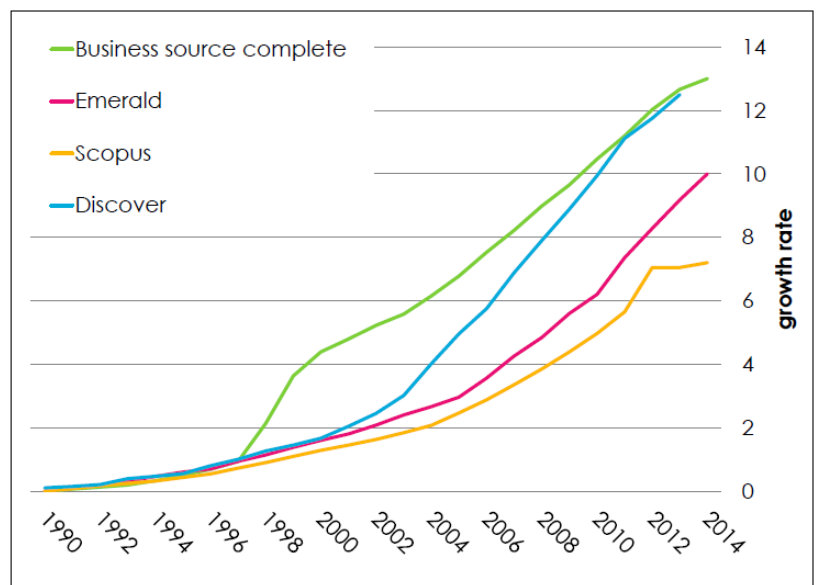

Figure 2: Growth rate of Management Publications relevant to Maturity [29]

\section{Previous Studies on Project Management Maturity:}

Perhaps, one of the first studies conducted in the field is the one conducted by Levene et al. in 1995. In this study, the maturity of three IT organizations has been evaluated. The main objective of the study was summarized as to develop a tool to inspect the level the organization had achieved their objectives and the project management practices implemented in the organization. The maturity levels of the three organizations were reported the same in the three organizations [11].

In 1997, Interthink Consulting Inc. has conducted a study on 65 Canadian organizations to evaluate their project management experience and capabilities. The study has considered five levels of maturity to evaluate the project management practices of the organizations. The study considered mainly the project management process of the organizations rather than the project performance and its objective mainly to propose an informative base for project management capabilities. The results of the study was summarized as seventy percent of these organizations were in level 2, only one organization out of the 65 organizations reached level three; while the rest of the organizations in level one [11]. 
Kwak and Ibbs conducted a study in 2000 to assess the organizational and financial impacts of project management on different organizations and industries. The study started by the development of a project management maturity model and an analysis methodology to assess the maturity of project management processes. The project management maturity analysis methodology consisted of 148 multiple choice questions which were divided over eight project management knowledge areas and six project phases to assess the project management maturity of the organizations. The maturity model and methodology were then implemented by benchmarking 38 different organizations and government agencies in 4 different industries. These industries are engineering and Construction, telecommunications, software development and the hi-tech manufacturing. The study took almost two years to gather the essential data required for the assessment. The authors have summarized the major acquisitions of their study as follows: development of a systematic methodology for the evaluation of the maturity of the project management practices and analysis of the strength and weakness of the project management practices among various industries and organizations. This study was recorded as a step towards a factual and quantitative methodology to evaluate the project management practices and performance for the organizations. Moreover, they also provided the organizations with some advices and proposal to enhance their project management practices [31].

Anderesen and Jessen in 2003 conducted a project management survey to investigate the level of project management maturity in organizations and to develop an understanding of what project maturity is. The authors used a questionnaire consisting of 36 statements, or questions, which all had the same weight. A scale of six choices was used in the research ranging from "completely disagree" [1] to completely agree [6]. The questionnaire has been implemented on 59 middle managers and project managers attending the master program of project management in the Norwegian school of management. The research hypothesis was that the project maturity develops through a maturity ladder where the ladder steps assumed to be project management, program management, and portfolio management. The authors examined the three levels of maturity project management, program management and portfolio management. The study findings are in line with the authors' hypothesis that the capability, or maturity level, at a higher stage of the maturity ladder (e.g. portfolio management) is less than the one at the lower stage of the maturity ladder (e.g. project management). Furthermore, the authors concluded that in general knowledge, attitudes, and action concerning changes are the overall prerequisites for developing a project mature organization [32].

Pennypacker and Grant conducted a study in 2003 [11] to provide a cross-industry benchmark of project management maturity to enable the organizations to evaluate their relative maturity in project management practices. In this research the authors adopted the PM solutions project management maturity model (PMS-PM3). The model consists of two dimensions. The first dimension is based on the knowledge areas of the project management institute (PMBOK PMI) and the second dimension is based on the SEI capability maturity model (CMM). The study was implemented on 123 organizations. The study concluded that almost $67 \%$ of the respondent organizations are at maturity level 2 (out of 5 levels) or even less. The detailed findings of the study can be summarized as follows: $13.7 \%$ of the respondent organizations are at maturity level 1 (initial process), 53.2\% at maturity level 2 (structured process and standards), $19.4 \%$ are at maturity level 3 - organizational standards and institutionalized process,$- 7.3 \%$ at level 4 (managed process) and only $6.5 \%$ at maturity level 5 (optimized process). Furthermore, the authors have also concluded that "the level of project management maturity is statistically consistent between industries and among companies of varying size" and stressed that to have a valid comparisons of the maturity of project management between different organizations and over time for the same organization, that requires to agree on a common project management maturity model, common techniques for the assessments, common level of analysis and common mythology for the analysis [11].

The above findings are in line with another study conducted by the same authors in 2006. In this study, the authors approached the center for Business Practices Consortium (CBP) with 
members over 900 senior practitioners in the field of project management. A number of 42 detailed components of maturity were assessed by utilizing a specific question for every project management component. The study was implemented among 126 organizations in North America in 17 distinct industries. The authors conclude that the median maturity level is two out of five levels with respect to 36 of the 42 components analyzed. Skimore and Bay in 2006, conducted a survey in Indonesia to reveal the project management maturity level in the country; they concluded that although project management has matured as a discipline in the country; however the project management practices had not been used effectively in the country [24]. Mullaly in 2006 conducted a long international survey from 1998 to 2003 on several organizations ranged from 280 to 579 organizations. The main findings of the study could be summarized as increase in the number of level 1 organizations and decrease in the number of organizations with level 2 or above [33]. A global study by a commercial party (pricewaterhouseCoopers) was conducted in 2004 on the level of project management maturity level across the world. The study was implemented among 200 organizations worldwide, where 3488 directors, project and portfolio managers have participated that were involved in almost 10600 projects with an estimated revenue of four and half billion USD / year. The main findings of the study can be outlined as follows [34]:

- A higher overall project performance is a result to a higher maturity level (i.e. the performance of the compete project portfolio)

- The average maturity level worldwide is 2.5 , which means that the maturity level is at the level of informal processes and hence the institutionalization is lacking. This is also one of the main reasons that many projects are unsuccessful.

- In the public sector the majority of organizations $(56.3 \%)$ only achieve maturity level 1 .

- A clear correlation exists between project performance, maturity level, and change management.

- A systematic approach to change management in projects is essential in excellent performance.

The PricewaterhouseCoopers conducted another similar study in 2012 and compared it to the study conducted in 2004. The study concluded that project management maturity was on rise. In 2012, the number of organizations in level 4 (Monitor) and in level 5 (optimize) have increase to become (as a percentage of the respondent organizations) $42.5 \%$ and $12.7 \%$ instead of $12.7 \%$ and $9.2 \%$ respectively, in 2004 study. Overall, in 2012, almost $62 \%$ of the respondent organizations were operating their business within level 4 and 5 compared to almost $78 \%$ of the respondent organizations were operating their business on level 1,2 and 3 [34] [35]. Prado and Archibald conducted extensive research on the status of project management maturity in Brazil in 2014. The research was conducted on 434 organizations and the results showed that the average maturity level was 2.6 on the (1-5) scale and only 9.9 $\%$ of the investigated organizations were at levels 4 and 5 [3]. Narbaev in 2015, conducted a study to assess the project management maturity in Kazakhstan, the study concluded that the average maturity level in the country is 2.42 on the (1-5) scale [2]. In the previous section, several academic and commercial studies related to the assessment of the project management maturity have been discussed. Each study has used different maturity model in its evaluation. Maturity models differ from each other in the concepts they embody and the suggestions they propose for the organizations to make the improvement [16-3]. With dozens of project management maturity models [2] [3] in the field of project management, It is crucial for contracting organizations to assess their level by a comprehensive and useful model [40]. Therefore, the first step towards achieving the objective of our study was to choose the most appropriate maturity model to be utilized in the Egyptian construction industry. Consequently, we have started to consider the various aspects of some of the most widely used models such as: CMM [41], CMMI [39], P3M3 model [36] [37], PMMM [22], Berkeley model [31], Prince 2 model [38], Kerzner model [20] [21] [19], PMI-OPM3 model [19].

\section{Project Management Maturity Models:}

To measure the project management maturity, several models have been developed and utilized during the last 2 decades. Although these models vary from simple to very complex, but they share the common goal whose objectives are to identify where the project 
management enhancements are needed, give clear indication of the strengths and weaknesses of the project management practices, lead to significant competitive advantages, and benchmark an organization against its competitors [18] [2]. The basis of the maturity models may extend to Crosby's model in 1979. Crosby structured his famous model known as QMMG, which stands to "the quality Management Maturity Grid". The model was based on 5 levels of maturity, which are linked to the adoption of quality principals within the organization. In 1986, Deming proposed several practices for the continuous improvement of quality management process within the organizations. These practices included the Deming Cycle (PDCA); which consist of four repeated stages: 1. Plan, 2.Do, 3.Check, and 4.Act. Based on the Crosby model and the Deming circle, a model to evaluate and encourage the management of software process was developed by United States defense department and the Software Engineering Institute (SEI) at Carnegie Mellon University. The model was known as the Capability Maturity Model (CMM). The development of CMM started in 1987 and the initial version was released in 1991. The main objective of the CMM is the enhancement of the processes conducted in the software engineering projects. The model consists of 5 levels of maturity for evaluation 18 process areas, 52 objectives, and over 300 key practices [14]. The success of the CMM in the software industry inspired experts in several fields including the project management field to develop several other maturity models; consequently several and valuable maturity models in the project management field have been developed during the last two decades. The (CMMI) stands for the Capability maturity model integration, which was released in 2000 as a successor to the CMM with more general application. CMMI integrates areas such as services, product development and software engineering. CMMI version 1.3, which was released in 2010, is currently covers three areas of interest and offers the following three maturity models: CMMI-SVC (capability maturity models for services), CMMI-DEV (Capability maturity model for development) and CMMI-ACQ (Capability maturity model for Acquisition) [23][42].

Harold Kerzner in 2001, proposed a maturity model to evaluate the project management maturity for organizations known as K-PMMM. The model has five levels and emphasizes benchmarking and makes benchmarking the forth level in the model. the author has identified the characteristic at every maturity level, the 'roadblocks', 'risks', and essential actions required to finish this level. The model is applied through a questionnaire - interview that consists of 183 questions and divide the results into various scores and considers the maturity model from the strategic planning point of view [43] [21].

Also, in 2001, the project Management Solution Software in the United States developed the PM Solutions-PMMM. As explained by Crawford, 2015, this model is created by mirroring ten knowledge areas of the PMBOK with that five level maturity stage of the CMM's. The model verifies an organization's PM realization across the ten Project Management knowledge areas, which are, on the other hand, divided into processes. In their handbook, [22] the model's developers have presented a comprehensive explanation of the attributes of the knowledge area at every maturity level [22]. The model is easy to understood and readily operational, and therefore was accepted easily. The project portfolio management maturity model (PMS-PPMMM) was released soon afterwards and added the portfolio dimension to the model.

The Advanced Engineering Association of Japan (ENAA) released in 2001 the P2M maturity model, which stands for the project and program management for enterprise innovation. The model is based on Kaikaku project management (KPM). In this model, the maturity is classified into five levels: Haphazard, Systematic, scientific, integrated and optimization. The model aimed to encourage the idea of Intellectual property for both managers and workers in preference to technology skills in project management [44].

In 2002, the project management process maturity model (Pm2) was introduced by the University of Berkeley (William C. Ibbs and Kwak) as a more comprehensive maturity model to evaluate and compare the maturity of the organizations. The model breakdowns Project Management processes and practices into Project Management knowledge areas and phases 
of processes adopting PMBOK's division. The model evaluates the project management maturity of an organization through the evaluation of those knowledge areas and phases [45].

In 1998, the PMI launched the development of the organizational project management maturity model program (OPM3) to pursue the recognition of this model as a global standard and it aims to help organizations to transfer strategy into successful performance. The OPM3 model is arranged in three elements connected together (knowledge; assessment; and improvement) and it covers three domains (portfolio management, program management and project management). The model has three interrelated components in every domain (best practices; capabilities; and outcomes) and has four stages of enhancement (SMCI), which are: standardize, measure, control and continuous improvement [19].

In 2004, the office of Government Commerce (OGC) launched a maturity model for the project dimension (PjM3). This later evolved into the Prince 2 maturity model, which specifically is maturity model for the organizations utilizing the Prince 2 methodology. In the same year Vienna University of economics and business administration introduced the Cobweb model; which is a six level maturity model for the self-assessment and benchmarking of organizations. In 2006, the OGC launched a complete version of P3M3 which includes portfolio, program and project management dimensions for any project based organization [2].

As stated by Axelos Limited (2013), the P3M3 provides a framework can evaluate the current performance of organizations and plan for improvement during managing and delivering change. The model has three sub models that may be used separately to focus on particular areas of business and more generally to assist organizations to evaluate the projects, programs and portfolios [36]. Therefore, P3M3 considers not only the activities carried out at the individual program and project level, but also the activities within the organization that provide focus and help sustain effort to build an infrastructure for effective management practices [36] [37].The IPMA Delta model integrates the state-of- the art know how covering a 360 degree perspective of organizational competence in PM. The standard comprises three domains. It uses the IPMA competence baseline to evaluate the competence of selected individuals (Module I) and the IPMA project excellence model to evaluate the project management competence and results in selected projects and programs (Module P). Finally, Module $\mathrm{O}$ is utilized to evaluate the organizational competence in managing projects based on the IPMA organizational competence base line standard (IPMA OCB) [46].

\section{COMPARISON OF MATURITY MODELS}

The above are the predominant project management maturity models, however with dozens of project management maturity models [2] [3] easily obtained in the area of project management, Construction contractors really need to take into consideration precisely which maturity model they can adopt. To be able to achieve this, contracting organizations have to know which aspects of these models are important to consider and also how they have to assess them. As concluded by (Wendler, 2012), "there is still a gap in evaluating and validating developed maturity models" [28]. Therefore the next step towards achieving the goal of our study is to define the most appropriate maturity model which can be adapted to be used for Contractors working in the Egyptian Construction Industry. Consequently, the purpose of this section is to compare the maturity models in terms of selected variables along with the strengths and weaknesses for each model. Thereby, offering a clear view to choose the most suitable one to be adopted and also facilitate the development of the required framework.

The maturity models selected from the literature for comparison have been selected based on specific selection criteria include:

- References and implementation in the literature is indexed under project management maturity models.

- Adequate practical and academic basis.

- Expert judgment related to the practical application of the models. 
- Publications: Sufficient coverage of models by academic and practical papers.

- Relative Simplicity and Ease of use.

- Number of existence years in the field.

- Transparency.

- Publicity.

- Public domain: To which degree the maturity model and maturity assessment can be implemented as a self-assessment by the organization, beside its owners.

- Method Independency: the degree the maturity models are closely aligned to a specific project management methodology.

Based on the above considerations, the following models have been selected: CMMI, OPM3, P3M3, KPMMM, PM2 and Prince 2(P2MM). As CMM is the first maturity model, and due to its success and it was the inspiration to most of the other models, it was also added to the comparison. A large detailed comparative table (Table 1) was produced to summarize the results of the study. The comparison study reveals the most common gaps among the maturity models. By observing these gaps; it could be summarized as follows:

- Staff competencies and skills are not measured.

- Each model has its jargon and terminology according to the standard followed.

- Social, economic, political and culture features are not considered.

- Extravagant Bureaucracy.

- Web based support is not provided for some important models.

By considering and analysis of these gaps, the integrated framework will respond and consider it.

\section{ANALYSIS OF THE CURRENT STATUS AND EXPERT JUDGEMENT}

In order to develop the framework that responds to the current status of contracting organizations working in the Egyptian construction industry, we must first understand their level of knowledge about the project management international standards and its methodologies along with the project management activities that have been carried out by these organizations. To conduct this study, we used the expert judgment gathered through a survey of industry professionals, which was sent to 143 Participants. The participants were most professionals and experts in project management working in the Egyptian contracting organizations working in the construction industry. An on-line survey was also developed and sent to other contracting organizations. The questionnaire survey was divided into three parts: the first part consists of 4 questions of personal nature to help position the respondent and the second part consists of 5 questions to help position the contracting organization. The third part consists of twelve questions related the contracting organization utilization of project management standards and maturity models. 
Table 01: Comparison of Maturity Models (continued)

\begin{tabular}{|c|c|c|}
\hline $\begin{array}{l}\text { Maturity } \\
\text { Model }\end{array}$ & (26) Strengths & (27) Weaknesses \\
\hline OPM3 & $\begin{array}{l}\text { - Global vision of the business is always maintained. } \\
\text { - Repetitive cycle of improvement is essential part of the model. } \\
\text { - Integrates organizational strategy with projects. } \\
\text { - Knowledge of best practices in project management is offered in the model. } \\
\text { - PMBOK is the base of the model, which inspires reliability and confidence. } \\
\text { - Considers the correlation between existing processes. }\end{array}$ & $\begin{array}{l}\text { - There is no internet access or software program to support the model. } \\
\text { - Political, economic, social or culture aspects are not considered. } \\
\text { - Benchmarking with other studies and other maturity models would be difficult, as it } \\
\text { identifies the percentage of organizational maturity rather than the maturity level } \\
\text { - It is different from the other maturity models, and it could be little bit difficult to } \\
\text { understand. }\end{array}$ \\
\hline P3M3 & $\begin{array}{l}\text { - Developed by OGC, which inspires confidence and reliability } \\
\text { - Easy Internet Access. } \\
\text { - }\end{array}$ & $\begin{array}{l}\text { - Political, economic, social or culture aspects are not considered. } \\
\text { - Social abilities are not considered. } \\
\text { - Organizational objectives are emphasized. }\end{array}$ \\
\hline P2MM & $\begin{array}{l}\text { - Developed by PRINCE, which inspires confidence and reliability? } \\
\text { - Easy Internet Access. } \\
\end{array}$ & $\begin{array}{l}\text { - Political, economic, social or culture aspects are not considered. } \\
\text { - Social abilities are not considered. }\end{array}$ \\
\hline Kerzner & $\begin{array}{l}\text { - Easy Internes Access. } \\
\text { - Organizational strategic planning is the main focus of the model. } \\
\text { - Implementation is simple and easy (Consists of } 183 \text { questions). } \\
\text { - Staff skills and competencies are measured. } \\
\text { - The last three levels in the model form repetitive cycle leading to excellence. } \\
\text { - Enables overlap and feedback between maturity levels. }\end{array}$ & $\begin{array}{l}\text { - Political, economic, social or culture aspects are not considered. } \\
\text { - Restriction of the Model to a single corporate culture. } \\
\text { - Needs and requirements of developing countries are not considered. } \\
\text { - Staff skills and competency are not measured. }\end{array}$ \\
\hline PM2 & $\begin{array}{l}\text { - PMBOK is the base of the model, which inspires reliability and confidence. } \\
\text { - Model understanding and implementation are easy and simple. } \\
\text { - Functional organizations are handled by the Model. } \\
\text { - Enables organizations to make comparison in the same industry. } \\
\text { - The Model provides relative level of maturity in comparison with other } \\
\text { organizations for benchmarking. }\end{array}$ & $\begin{array}{l}\text { - Political, economic, social or culture aspects are not considered. } \\
\text { - Social abilities are not considered. }\end{array}$ \\
\hline CMMI & $\begin{array}{l}\text { - A set of Best practices based on the lessons learned and the successful cases is } \\
\text { offered by the Model. } \\
\text { - A method for integrating organizational functional elements is offered by the } \\
\text { model. }\end{array}$ & $\begin{array}{l}\text { - Political, economic, social or culture aspects are not considered. } \\
\text { - Staff skills and competency are not measured. } \\
\text { - Too long processes. } \\
\text { - Extremely bureaucratic } \\
\text { - Staff with considerable experience or excessively expensive training is required. } \\
\text { - Almost works exclusively with organizational processes. }\end{array}$ \\
\hline CMM & $\begin{array}{l}\text { - Very useful and interesting for software organizations. } \\
\text { - Defines areas where enhancement is required. } \\
\text { - Its success inspires the development of the other maturity models. } \\
\text { - One of the best known models. }\end{array}$ & $\begin{array}{l}\text { - Political, economic, social or culture aspects are not considered. } \\
\text { - Staff skills and competency are not measured. } \\
\text { - Staff with considerable experience is required. } \\
\text { - Rigid Procedures. } \\
\text { - Extremely bureaucratic } \\
\text { - Exclusive in software maintenance and development processes }\end{array}$ \\
\hline
\end{tabular}


The questions in the survey are related to the major famous international project management standards and maturity models. The respondent were always given the choice to state that they utilize other standards or systems not indicated, or don't know the answer or that they are not sure to answer satisfactorily; thus, avoiding forced or unrealistic answers.

The preliminary results of the questionnaire survey have started to be received. A comprehensive analysis of the survey will be conducted in future work after receiving all the expected responses.

However, from the analysis of the preliminary results and the samples received till date, it can be concluded that Egyptian contracting organizations are generally unaware of the value of the maturity models. The respondents also mentioned that the processes of maturity models have never been implemented in their organizations. Therefore, gaps, deficiencies and lessons learned from their implementation cannot be identified.

\section{PROPSED MATURITY MODEL}

In this section, the guidelines for the development of integrated frame work for appraisal and improvements of contracting organizations working in the Egyptian construction industry is proposed [AIPMC2] based on the comparative study of the existing predominant models and the preliminary results of the questionnaire survey received till date. The objective of this basis is to remedy the gaps identified in the first study and to meet the requirements observed from questionnaire survey of the current status. While these bases are preliminary and will be further developed in future work, the following specific gaps noted from the comparative study are proposed to be covered:

- Following the PMBOK ( $5^{\text {th }}$ Edition) guidelines and terminology to guarantee having a common language.

- Supporting the integrated framework by a web based module for self-assessment.

- Evaluation of staff skills and competencies.

- Simplify the procedures for the appraisal.

- Political, economic, social and cultural characteristics should be considered in the model.

The preliminary results of the questionnaire survey show the need to develop an integrated framework that assumes a lack of project management standardization by contracting organizations and to be accessible for any size of organizations. The basic framework is proposed that will be later extended to include all the project management dimensions (portfolios, programs, and projects). The starting assumption is that some Egyptian contracting organizations lack training in this area and will be starting from level 0 . By building on the Deming circle, continuous enhancements on the road to excellence are assumed. With these assumptions, the proposed integrated framework is presented in Fig 3. As shown in the figure, the PDCA circle rotates as the maturity level rises for all required actions necessary at all stages and situations of the project and organization. The maturity of the organization is raised from unawareness of the tools and techniques of project management (level 0) to process optimization (Level 5), in which all the project management knowledge areas are evaluated at each maturity level and actions are taken to increase the maturity level. The summarized maturity levels in AIPMC2 are as follows:

Level 0 : The organization is unaware of project management and its tools and Techniques.

Level 1 : Although the organization is aware of project management and the need for it, but there are no established practices or standards, and project managers are not held to specific accountability by any process standards. Documentation is loose and ad hoc. Metrics are informally collected on an ad hoc basis.

Level 2 : Many project management processes exist within the organization, but they are not considered organizational standards. Documentation exists on these specific basic processes. Management supports the implementation of project management, but there is neither consistent understanding and involvement nor organizational mandate 
for compliance on the organizational level. There are basic metrics to track project cost, schedule and technical performance, although data may be collected or correlated manually.

Level 3 : In this level, the project management processes are in place and established as organizational standards.

Level 4 : Project Management Processes, standards and supporting systems are integrated with other corporate processes and systems. Estimates related to performance, cost and time are generally achieved.

Level 5 : Processed towards continuous improvement are reviewed and adapted. The level of success is generally $100 \%$.

For the evaluation, the maturity level was assessed for each of the ten knowledge areas established by the PMBOK [47] along with the four knowledge areas in the construction extension [48]. The maturity level of the organization is considered to be the lowest value obtained in all knowledge areas, as the raise in the level of maturity of the organization can't be achieved until all the requirements in every knowledge area are met. The integrated Framework for Appraisal and Improvement of Construction Contractors [AIPMC2] is applicable to all construction contracting organizations, even if these organizations are unaware of project management or doesn't apply its principles.
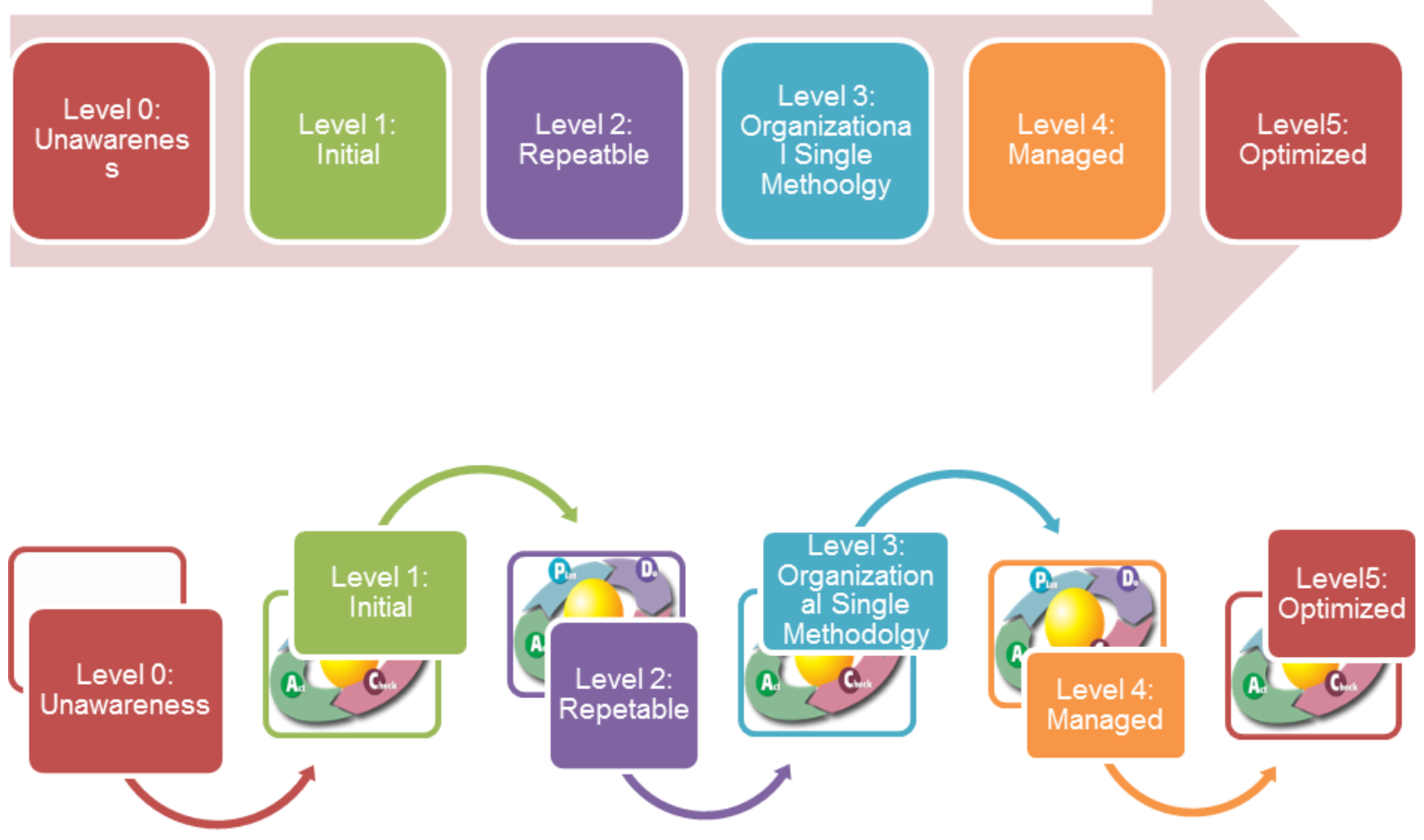

Figure 3: Summary of Maturity Levels in AIPMC2

As a summary, AIPMC2 is integrated framework for appraisal and improvement of project management practices for contracting organizations working in the Egyptian construction industry with any size that wish to make a continuous improvement of their performance by implementing detailed processes and systems to ensure the success of construction projects. 


\section{CONCLUSION, THE WAY FORWARD AND FURTHER STEPS}

Following the review of the literature related to the academic and practitioner's studies conducted in different countries on the appraisal and improvement of project management practices, it was found that the maturity concept has been expanded, evolved and became a well-received technique globally and widely implemented in various industries worldwide. The maturity concept, basics definitions and evolution during the last two decades have been reviewed and documented. Moreover, the study of the existing predominant maturity models have been conducted and followed by distribution of a questionnaire survey to assess the current status in the Egyptian construction industry. Some sample replies have been received. From the preliminary results, we can say that the concepts and practices of project management maturity in Egypt are at its very early initial stage of its existence. From the above, we can conclude that contracting organizations working in the Egyptian construction industry would have a lot of benefits from implementation of a maturity model adapted to the current situation found in the Egyptian Construction Industry. This work also has established and proposed the theoretical basis for the maturity model adapted to meet these requirements. This integrated framework will be developed as a future work.

\section{REFERENCES}

1. Ofori, G. (2006). Construction in developing countries: A research agenda, Journal of Construction in Developing Countries.

2. Narbaev, T. (2015). An Assessment of Project Management Maturity in Kazakhstan.

3. Archibald, R. D., \& Prado, D. (2014). The Importance of Knowing Your Project, Program, and Portfolio Management Maturity: PPPMM.

4. Idoko, L. A. (2008). Developing local capacity for project management - Key to social and business transformation in developing countries. PMI Global Congress 2008. Project Management Institute.

5. "Youm 7 Daily Newspaper", http://m2.youm7.com/story/2015/8/4, (2015), accessed August 4, 2015.

6. Adams, O. (1997). Contractor development in Nigeria: Perceptions of contractors and professionals. Journal of Construction Management and Economics, 15(1), 95- 108.

7. Long, N. D., Ogunlana, S., Quang, T., \& Lam, K. C. (2004). Large construction projects in developing countries: A case study from Vietnam. International Journal of Project Management, 553-561.

8. Dlungwana, W. S., \& Rwelamila, P. D. (2004). CONTRACTOR DEVELOPMENT MODELS THAT MEET THE CHALLENGES OF GLOBALISATION-A CASE FOR DEVELOPING MANAGEMENT CAPABILITY OF LOCAL CONTRACTORS. Globalization and Construction, 347.

9. Cleland, D. I., \& Ireland, L. (2002). Project management: Strategic Design and Implementation: McGraw-HilI. New York.

10. Grant, K.P. \& Pennypacker, J.S. (2006). Project management maturity: an assessment of project management capabilities among and between selected industries [electronic version]. IEEE Transactions on Engineering Management, 53(1), 59-68.

11. Pennypacker, J. S., \& Grant, K. P. (2003). Project management maturity: An industry benchmark. Project Management Journal, 34(1), 4-11.

12. Cooke-Davies, T. J. (2005). Measurement of organizational maturity: What are the relevant questions about maturity and metrics for a project-based organization to ask, and what do these imply for project management research? In P. M. (PMI).

13. Skulmoski, G. (2001). Project maturity and competence interface. COST ENGINEERING-ANN ARBOR THEN MORGANTOWN-, 43(6), 11-24.

14. Paulk, M. C., Curtis, B., Chrissis, M. B., \& Weber, C. V. (1993). The capability maturity model for software, version1.1. Technical Report, Carnegie Mellon University, Software Engineering Institute, Pittsburg.

15. Kwak, Y. H. and C. W. Ibbs (2000), "Calculating Project Management's Return on Investment" Project Management Journal, Vol. 31, Issue 2, p 38. 
16. Bolles, D. (2002), "Building Project Management Centers of Excellence" AMACOM, Vol. 1, US.

17. PM Solutions. (2008). Advancing organizational project management maturity. Retrieved November 2, 2015, from PM Solutions website: http://www.pmsolutions.com/collateral/uploads/pdfs/White\%20Paper_Advancing\%20PM $\%$ 20Maturity.pdf.

18. Archibald, R., Prado, D. (2014). Introduction to maturity in project management. PM World Journal, 3(1), 1-14.

19. Project Management Institute (PMI). (2013). Organizational Project Management Maturity Model (OPM3®) (3rd Ed.). Newtown Square, Pa: Project Management Institute.

20. . Kerzner, H. (2004). Advanced project management: Best practices on implementation. John Wiley \& Sons.

21. Kerzner, H. R. (2002). Strategic planning for project management using a project management maturity model. John Wiley \& Son.

22. Crawford, J. K. (2015). Project management maturity model. CRC Press.

23. Chrissis, M. B., Konrad, M., \& Shrum, S. (2003). CMMI: Guidelines for process integration and product improvement. Addison Wesley.

24. Supic, H. (2005). Project management maturity of selected organizations in Croatia. Proceedings of the 8th International Conference on Telecommunications ConTEL 2005, 2, pp. 647-653. Zagreb.

25. Sarshar, M., Haigh, R., Finnemore, M., Aouad, G., Barrett, P., Baldry, D., et al. (2000). SPICE: a business process diagnostics tool for construction projects. Engineering Construction and Architectural Management, 7(3), 241-250.

26. Kaya, Y., \& Iyigun, I. (2001). Case Study: Assessment of R\&D project management maturity and improvement in project management process. Management of Engineering and Technology, 2001. PICMET '01, 1, pp. 416-417.

27. Saiedia, H., \& Kuzara, R. (1995, January). SEI capability maturity model's impact on contractors. Computer, 28(1), 16-26.

28. Wendler, R. (2012). The maturity of maturity model research: A systematic mapping study. Information and software technology, 54(12), 1317-1339.

29. Nesensohn, C., Bryde, D. J., Ochieng, E., \& Fearon, D. (2014). Maturity and maturity models in lean construction. Construction Economics and Building, 14(1), 45-59.

30. Eadie, R., Perera, S. and Heaney, G. (2012) 'Capturing maturity of ICT applications in construction processes', Journal of Financial Management of Property \& Construction, 17 (2), 176-94.

31. Kwak, Y. H., \& William, C. (2000). The Berkeley project management process maturity model: measuring the value of project management. In Engineering Management Society, 2000. Proceedings of the 2000 IEEE (pp. 1-5). IEEE.

32. Andersen, E. S., \& Jessen, S. A. (2003). Project maturity in organizations. International journal of project management, 21(6), 457-461.

33. Mullaly, M. (2006). Longitudinal analysis of project management maturity. Project Management Journal, 37(3), 62.

34. Nieto-Rodriguez, A. and Evrard, D. (2004). Boosting business performance through program and project management: A first global survey on the current state of project management maturity in organizations across the world, PricewaterhouseCoopers, Sint-St.

35. PriceWaterhouseCoopers. (2012). Insights and trends: Current portfolio, program, and project management practices. The third global survey on the current state of project management. Retrieved from

http://www.pmi.org/ /media/PDF/RCP/PwC_PPPM_Trends_2012.

36. Axelos Limited. (2015b). Portfolio, program and project management maturity model (P3M3® version 3.0): Introduction and guide to P3M3®. Axelos Limited, London.

37. Axelos Limited. (2015a). Portfolio, program and project management maturity model (P3M3® version 3.0): Project model. Axelos Limited, London.

38. Williams, G. (2013), "PRINCE2 Maturity Model (P2MM)", GSW Consultancy Limited, UK. 
39. Huang, S. J., \& Han, W. M. (2006). Selection priority of process areas based on CMMI continuous representation. Information \& Management, 43(3), 297-307.

40. Khoshgoftar, M., \& Osman, O. (2009, August). Comparison of maturity models. In Computer Science and Information Technology, 2009. ICCSIT 2009. 2nd IEEE International Conference on (pp. 297-301). IEEE.

41. Curtis, D. B., Hefley, W. E., \& Miller, S. A. (2002). The people capability maturity model: Guidelines for improving the workforce. Addison-Wesley.

42. Ahern, D. M., Clouse, A., \& Turner, R. (2008). CMMI distilled: A practical introduction to integrated process improvement (3rd Ed.). Upper Saddle River, NJ: Addison- Wesley Professional.

43. IIL. (2015). Kerzner PM maturity assessment. International Institute for Learning, Inc. Retrieved from http://www.iil.com/kpm3/how_kpm3_works.asp.

44. Ohara, S. (2005). P2M Guidebook. Retrieved from http://www.pmaj.or.jp/ENG/index.htm.

45. Kwak, Y.H. \& Ibbs, C.W. (2002). Project management process maturity (PM) 2 Model [electronic version]. Journal of Management Engineering, 18(3), 150-155.

46. International Project Management Association. (2015). The IPMA Delta Model. Retrieved from http://ipma.ch/certification/certify-organisations/delta-reference-model/

47. Project Management Institute (PMI). (2013). A guide to the project management body of knowledge (PMBOK guide) (5th Ed.). Newtown Square, Pa: Project Management Institute.

48. Project Management Institute. (2008). Construction extension to a guide to the project management body of knowledge, 3rd edition. Newtown Square, Pa: Project Management Institute. 